\title{
Individual-level data on the relationships of progression-free survival, post-progression survival and tumor response with overall survival in patients with advanced non-squamous non-small cell lung cancer
}

\author{
H. IMAI ${ }^{1}$, T. TAKAHASHI ${ }^{1, *}$, K. MORI $^{2}$, A. ONO ${ }^{1}$, H. AKAMATSU ${ }^{1}$, T. SHUKUYA ${ }^{1}$, T. TAIRA ${ }^{1}$, H. KENMOTSU ${ }^{1}$, T. NAITO $^{1}$, H. MURAKAMI $^{1}$, \\ M. ENDO ${ }^{3}$, T. NAKAJIMA ${ }^{4}$, N. YAMAMOTO ${ }^{1,5}$
}

${ }^{1}$ Division of Thoracic Oncology, ${ }^{2}$ Clinical Trial Coordination Office, ${ }^{3}$ Division of Diagnostic Radiology, ${ }^{4}$ Division of Diagnostic Pathology, Shizuoka Cancer Center, 1007 Shimonagakubo, Nagaizumi-chou, Suntou-gun, Shizuoka 411-8777, Japan; ${ }^{5}$ Third Department of Internal Medicine, Wakayama Medical University, 1-811, Kimiidera, Wakayama-shi, Wakayama 641-8509, Japan

*Correspondence: t.takahashi@scchr.jp

Received June 24, 2013 / Accepted August 21, 2013

\begin{abstract}
The effects of first-line chemotherapy on overall survival (OS) might be confounded by subsequent therapies in patients with non-small cell lung cancer (NSCLC). We examined whether progression-free survival (PFS), post-progression survival (PPS), or tumor response could be valid surrogate endpoints for OS after first-line chemotherapies in advanced NSCLC by using individual-level data, given the lack of research in this area. Between April 2009 and June 2011, 50 patients with advanced non-squamous NSCLC treated with cisplatin and pemetrexed as first-line chemotherapy were analyzed. The relationships of PFS, PPS, and tumor response with OS were analyzed at the individual level. Spearman rank correlation analysis and linear regression analysis showed that PPS was strongly correlated with OS $\left(r=0.89, P<0.05, R^{2}=0.79\right)$, PFS was moderately correlated with OS $\left(r=0.67, P<0.05, R^{2}=0.39\right)$, and tumor shrinkage was weakly correlated with OS $(r=0.36, P<0.05$, $\left.R^{2}=0.14\right)$. Performance status at the beginning of second-line treatment, the best response to second-line treatment, and number of regimens used after progression following first-line chemotherapy were significantly associated with PPS $(P<$ 0.05). Analysis of individual-level data suggested that PPS could be used as a surrogate for OS in patients with advanced nonsquamous NSCLC with unknown oncogenic driver mutations and therefore limited options for subsequent chemotherapy. Our findings also suggest that subsequent treatment after disease progression following first-line chemotherapy may greatly influence OS. These results should be validated in other larger populations.
\end{abstract}

Key words: non-small cell lung cancer, overall survival, post-progression survival, progression-free survival, tumor response

Lung cancer is the most common cause of cancerrelated mortality worldwide, with non-small cell lung cancer (NSCLC) accounting for approximately $85 \%$ of lung cancers [1]. Overall survival (OS) is considered the most reliable endpoint in cancer studies, and when studies can be conducted to adequately assess survival, it is usually the preferred endpoint [2]. This endpoint is precise, easy to measure, and can be documented by the date of death. Surrogate endpoints such as tumor response and progression-free survival (PFS) are also useful endpoints for phase II oncology clinical trials because they can be measured earlier, can be measured more conveniently, and occur more frequently than the main endpoints of interest, which are referred to as the true endpoints.
In view of the growing number of drugs and combinations thereof that are available for the treatment of NSCLC, the effects of first-line chemotherapy on OS might be confounded by subsequent therapies [3]. Indeed, PFS improvements do not necessarily result in an improved OS, as shown by recent randomized trials in patients with NSCLC [4]. In recent years, as for breast, ovarian, and colorectal cancers [5-7], a growing number of active compounds are available for second- or third-line chemotherapy for advanced NSCLC. Although PFS following first-line chemotherapy has not been validated as a surrogate endpoint for OS, post-progression survival (PPS) has been shown to be strongly associated with OS after first-line chemotherapy for advanced NSCLC $[8,9]$. PPS has also come to be strongly associated with OS during the last 


\section{April 2009 June 2011 Cisplatin + pemetrexed first-line chemotherapy \\ (except maintenance therapy)}

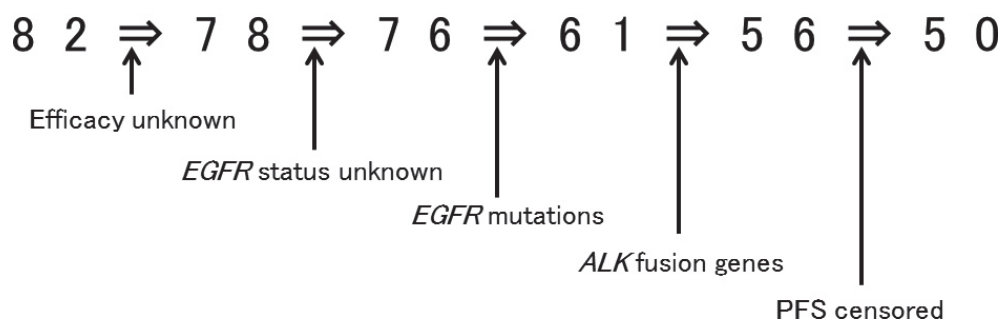

Figure 1. Flow chart showing patient selection.

decade (2002-2012) when molecular targeted agents such as gefitinib and erlotinib were introduced as chemotherapeutic agents for advanced NSCLC [8,9]. The evaluation of PPS by using a simple method was first reported in 2009 [2]: OS was expressed as the sum of PFS and PPS.

At the individual level, the effect of therapies administered after disease progression on survival is of interest. To date, the validation of surrogate measures for OS after first-line therapy, at the individual level, in patients with advanced NSCLC has not been reported. Further, the surrogate endpoint sometimes does not reflect the primary endpoint. Therefore, examination of whether PFS, PPS, or tumor response could be valid surrogate endpoints for OS after first-line therapy in patients with advanced NSCLC using individual-level data might be of clinical importance.

Platinum-based doublet chemotherapy is the standard of care for advanced NSCLC, based on modest benefits in survival and quality of life as compared with best supportive care only [10-15]. Although many patients initially achieve clinical remission or disease control with first-line chemotherapy, most subsequently experience disease progression and eventually die of advanced NSCLC. We examined first-line cisplatin and pemetrexed combination chemotherapy because this combination is considered standard first-line chemotherapy for advanced NSCLC [15]. Recently, in a phase 3 study of advanced NSCLC, first-line chemotherapy with pemetrexed plus cisplatin was more effective for patients with adenocarcinoma and large cell carcinoma than was gemcitabine/cisplatin (median survival of 11.8 versus 10.4 months, $P=0.005$ ) [15]. The median survival time (MST) of patients harboring an EGFR mutation treated with gefitinib, platinum, and pemetrexed or docetaxel was reported to be approximately 3 years [16]. However, the MST of patients without an EGFR mutation was approximately 1 year. For advanced NSCLC patients without oncogenic driver mutations, such as an EGFR mutation, OS is shorter and options for subsequent chemotherapy is currently limited.

In the present study, we analyzed the relationships of PFS, PPS, and tumor response with OS in patients with advanced non-squamous NSCLC at the individual level. The patients evaluated had unknown oncogenic driver mutations, and therefore, options for subsequent-line chemotherapy were limited. We also explored the prognostic value of baseline and tumor characteristics for PPS.

\section{Patients and methods}

Patients. Between April 2009 and June 2011, 82 patients with advanced non-squamous NSCLC were treated with cisplatin and pemetrexed as first-line chemotherapy and were enrolled in this study. The tumor response was not evaluated in 4 patients, an unknown EGFR mutation status was noted in 2, an EGFR mutation was observed in 15, the ALK fusion gene was identified in 5, and PFS data were censored in 6 . These 32 patients were excluded from the analyses to unify patient background. Patients receiving maintenance therapy were also not considered. Thus, data from 50 patients were analyzed (Figure 1). The study protocol was approved by the Institutional Review Board of Shizuoka Cancer Center (\#.24J82-24-1-3).

Patients in this study were treated with cisplatin $\left(75 \mathrm{mg} \cdot \mathrm{m}^{-2}\right.$ day $\left.{ }^{1}\right)$ and pemetrexed $\left(500 \mathrm{mg} \cdot \mathrm{m}^{-2} \mathrm{day}^{-1}\right.$ for $1 \mathrm{day}$, followed by a pause of 21 days). This cycle was repeated every 21 days for 6 courses.

The best overall response and maximum tumor shrinkage were recorded as tumor responses. Radiographic tumor responses were evaluated according to the Response Evaluation Criteria In Solid Tumors, ver. 1.1 [17]: complete response (CR), disappearance of all target lesions; partial response (PR), at least a 30\% decrease in the sum of the target lesion diameters with the summed baseline diameters as a reference; progressive disease (PD), at least a $20 \%$ increase in the sum of the target lesion diameters with the smallest sum observed during the study serving as reference; and stable disease (SD), insufficient shrinkage to qualify as PR and insufficient expansion to qualify as PD. PFS was calculated from the start of treatment to the date of PD or death from any cause. OS was recorded from the first day of treatment until death or was censored on the 


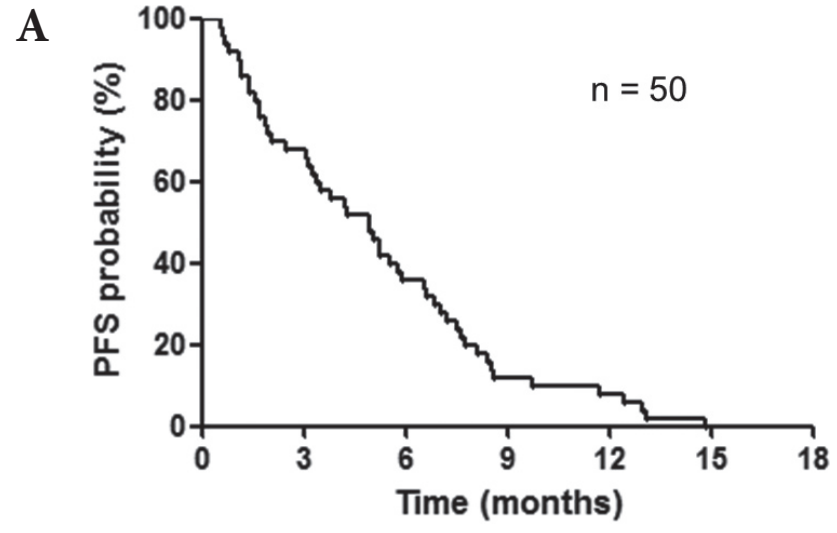

Median progression-free survival; 4.9 months
B

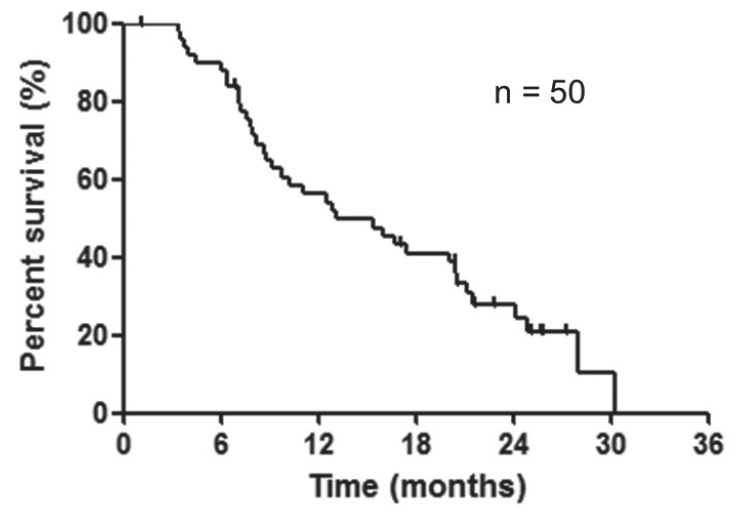

Median overall survival: 13.0 months, median follow up days: 12.6 months

Figure 2. A. Kaplan-Meier plots showing progression-free survival (PFS). B. Kaplan-Meier plots showing overall survival (OS).

date of the last follow-up consultation. PPS was recorded as the time from tumor progression until death or was censored on the date of the last follow-up consultation.

Statistical analysis. To examine whether PFS, PPS, or tumor shrinkage was correlated with OS, we used Spearman rank correlation analysis and linear regression analysis. To explore prognostic factors for PPS, the proportional hazards model with a stepwise regression procedure was applied. Hazard ratios (HR) and 95\% confidence intervals (CI) were estimated using the model. Because the HR is defined for a 1unit difference, some factors were converted to an appropriate scale unit. PPS values were compared using the log-rank test. A $P$ value of $\leq 0.05$ was considered significant for all tests. The two-tailed significance level was also set at 0.05 . All statistical

Table 1. Baseline patient characteristics.

\begin{tabular}{lc}
\hline Characteristic & \\
\hline Gender & $37 / 13$ \\
$\quad$ Male/female & $64(40-76)$ \\
Median age at treatment (years) & \\
Performance Status (PS) & $19 / 31 / 0$ \\
$\quad 0 / 1 / \geqq 2$ & \\
Histology & $47 / 3$ \\
$\quad$ Adenocarcinoma/others & \\
Stage & $4 / 46$ \\
$\quad$ IIIB/IV & $5 / 10 / 1 / 22 / 2 / 10$ \\
Number of first-line chemotherapy courses & \\
$\quad 1 / 2 / 3 / 4 / 5 / 6$ & \\
Number of regimens after progression following & \\
first-line chemotherapy & $10 / 18 / 11 / 4 / 5 / 1 / 1$ \\
$\quad 0 / 1 / 2 / 3 / 4 / 5 / 6$ & $1(0-6)$ \\
$\quad$ Median (range) & $57(22-185)$ \\
$\begin{array}{l}\text { Median sum of target lesion diameters [mm } \\
\text { (range) }\end{array}$
\end{tabular}

analyses were performed using JMP version 9.0 for Windows (SAS Institute, Cary, NC, USA).

\section{Results}

Patient characteristics and treatment efficacy. Of the 50 patients included in the analyses, 37 patients died; the median follow-up time was 12.6 months (range, 1.0-27.9 months). The characteristics of the 50 patients (median age, 64 years; range, 40-76 years) included in the present study are shown in Table 1. Target lesions were not evaluated in one patient.

In the 50 patients, 15,21 , and 14 showed $\mathrm{PR}, \mathrm{SD}$, and $\mathrm{PD}$, respectively. The response rate was $30.0 \%$ and the disease control rate was $72.0 \%$.

After progressing past first-line chemotherapy, 10 of the 50 patients did not receive post-chemotherapy. The other 40 patients received subsequent chemotherapy after completing their first-line chemotherapy. Among the 50 patients, the median number of follow-up therapeutic regimens was one (range, $0-6$ regimens). The chemotherapy regimens employed, after progressing past the first-line chemotherapy regimen, are shown in Table 2. The administration of docetaxel was most common in second-line chemotherapy, and the administration of amrubicin was the most common third-line chemotherapy.

The median PFS and OS were 4.9 months and 13.0 months, respectively (Figures. 2A, B).

Relationship between overall survival and progression-free survival, post-progression survival, and tumor shrinkage. The relationship between OS and PFS, PPS, and tumor shrinkage is shown in Figures 3A, 3B, and 3C, respectively. PPS was strongly associated with OS $(r=0.89, P<0.05$, $R^{2}=0.79$ ), based on Spearman's rank correlation coefficient and linear regression, whereas PFS was moderately correlated with OS ( $r=0.67, P<0.05, R^{2}=0.39$ ). Furthermore, tumor 
A

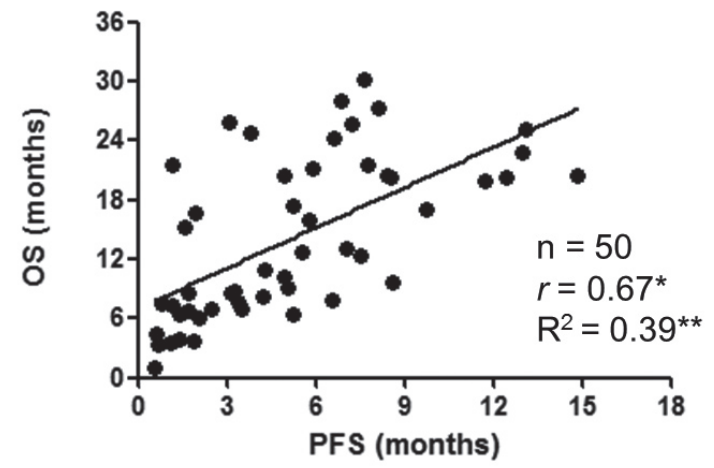

* The $r$ values represent Spearman's rank correlation coefficient ** The $\mathrm{R}^{2}$ values represent Linear regression

B

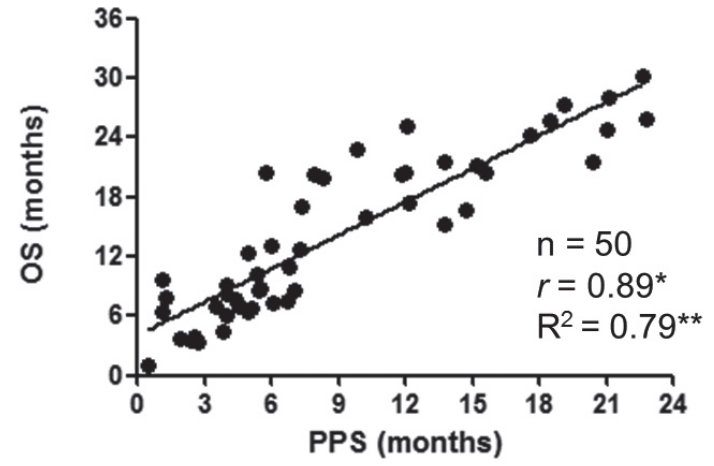

* The $r$ values represent Spearman's rank correlation coefficient ${ }^{\star \star}$ The $\mathrm{R}^{2}$ values represent Linear regression

C

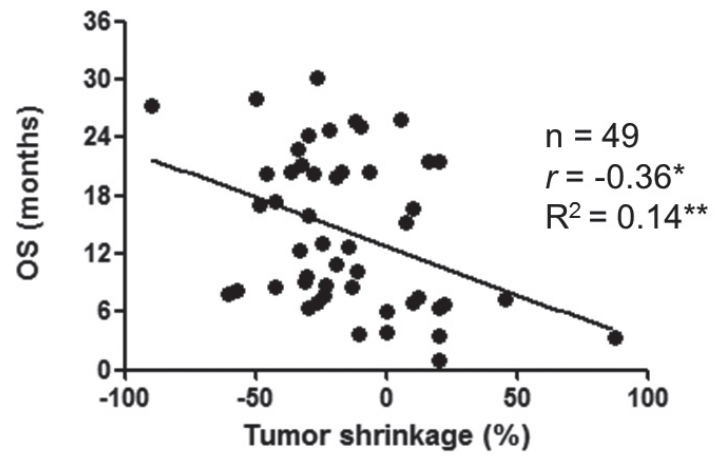

* The $r$ values represent Spearman's rank correlation coefficient ${ }^{\star \star}$ The $\mathrm{R}^{2}$ values represent Linear regression

Figure 3. A. Correlation between overall survival and progression-free survival. B. Correlation between overall survival and post-progression survival. C. Correlation between overall survival and tumor shrinkage.

shrinkage was only weakly correlated with OS $(r=0.36, P<$ $0.05, R^{2}=0.14$ ).

Factors affecting post-progression survival. PPS was strongly associated with OS. Therefore, the association between PPS and various clinical factors was assessed. In the
Table 2. The chemotherapy regimens employed after progression following first-line chemotherapy.

\begin{tabular}{lccc}
\hline & second-line & $\geqq$ third-line & Total \\
\hline Docetaxel & 18 & 8 & 26 \\
Erlotinib & & & \\
$\quad$ Single agent & 2 & 6 & 8 \\
Erlotinib \pm investigational agent & 2 & 2 & 4 \\
Others & & & \\
$\quad$ Single agent & 8 & 23 & 31 \\
$\quad$ S1 & 5 & 6 & 11 \\
$\quad$ Amrubicin & 0 & 10 & 10 \\
$\quad$ Others & 3 & 7 & 10 \\
Platinum combination & 10 & 2 & 12 \\
Investigational agent & 0 & 2 & 2 \\
\hline
\end{tabular}

univariate analysis (Table 3), the performance status (PS) at the beginning of first-line treatment, at the end of first-line treatment, and at the beginning of second-line treatment, as well as the best response from the second-line treatment and the number of regimens employed after progression beyond first-line chemotherapy were found to be associated with PPS $(P<0.05)$. Next, a multivariate analysis for PPS was conducted to clarify which clinical factors could affect PPS (Table 4). The PS at the beginning of the second-line treatment, the best response after the second-line treatment (non-PD/PD), and the number of regimens employed after progression following first-line chemotherapy were significantly associated with PPS $(P<0.05)$.

The log-rank tests confirmed that differences in PPS were observed in patients according to their PS at the beginning of second-line treatment, their best response at second-line treatment (non-PD/PD), and the number of regimens employed after progression following first-line chemotherapy. These 3 factors were significantly associated with PPS (log-rank test, $P<0.05$ (Figures $4 \mathrm{~A}, 4 \mathrm{~B}$, and $4 \mathrm{C}$ ). According to the PS at the beginning of second-line treatment, the PPS for those with PS 0 was 21.8 months, PS 1 was 6.7 months, and PS 2 was 1.3 months, respectively (log-rank test, $P<0.001$. Figure $4 \mathrm{~A})$. Furthermore, patients with non-PD had a median PPS of 15.6 months compared with their counterparts with PD of 4.9 months, respectively, (log-rank, $P<0.001$; Figure 4B). According to the number of regimens employed after progression following first-line chemotherapy, the PPS for those without additional regimens was 4.4 months; with 1 additional regimen, the PPS was 5.7 months; and with $\geqq 2$ regimens, the PPS was 13.7 months, (log-rank test, $P=0.013$; Figure 4 C). These results remained consistent after adjustment in the Cox proportional hazards models (Table 4 ).

\section{Discussion}

We examined the relationships of OS with PFS, PPS, and tumor shrinkage at the individual level. PPS was strongly 
Table 3. Univariate Cox regression analysis of baseline patient characteristics.

\begin{tabular}{|c|c|c|c|}
\hline \multirow[b]{2}{*}{ Factors } & \multicolumn{3}{|c|}{ Post-progression survival } \\
\hline & Hazard ratio & $95 \% \mathrm{CI}$ & $P$ value \\
\hline Gender & 1.36 & $0.65-3.09$ & 0.418 \\
\hline Age (years) at the beginning of first-line treatment & 1.02 & $0.94-1.02$ & 0.331 \\
\hline PS at the beginning of first-line treatment & 2.03 & $1.02-4.32$ & 0.042 \\
\hline Histology & 0.42 & $0.14-1.78$ & 0.208 \\
\hline Stage & 2.14 & $0.64-13.2$ & 0.240 \\
\hline Number of courses of first-line treatment administered & 0.82 & $0.65-1.04$ & 0.113 \\
\hline Sum of target lesion diameters & 1.00 & $0.99-1.01$ & 0.216 \\
\hline \multicolumn{4}{|l|}{ Best response at first-line treatment } \\
\hline $\mathrm{PR} /$ non-PR & 0.87 & $0.41-1.74$ & 0.716 \\
\hline non-PD/PD & 0.63 & $0.31-1.40$ & 0.249 \\
\hline PS at the end of first-line treatment & 2.63 & $1.46-4.72$ & 0.001 \\
\hline Age at the beginning of second-line treatment & 0.97 & $0.93-1.02$ & 0.344 \\
\hline PS at the beginning of second-line treatment & 7.74 & $2.54-32.1$ & $<0.001$ \\
\hline \multicolumn{4}{|l|}{ Best response following second-line treatment } \\
\hline $\mathrm{PR} /$ non-PR & 0.19 & $0.03-0.68$ & 0.007 \\
\hline non-PD/PD & 0.12 & $0.04-0.30$ & $<0.001$ \\
\hline Number of regimens after progression beyond first-line chemotherapy & 0.71 & $0.53-0.93$ & 0.011 \\
\hline
\end{tabular}

95\% CI, 95\% confidence interval; PS, performance status; PR, partial response; PD, progressive disease

Table 4. Multivariate Cox regression analysis for performance status (PS) at the beginning of first-line treatment, PS at the beginning of second-line treatment, best response following second-line treatment, and number of regimens employed after progression beyond first-line chemotherapy.

\begin{tabular}{|c|c|c|c|}
\hline \multirow[b]{2}{*}{ Factors } & \multicolumn{3}{|c|}{ Post-progression survival } \\
\hline & Hazard ratio & $95 \% \mathrm{CI}$ & $\mathrm{P}$ value \\
\hline PS at the beginning of first-line treatment & 1.68 & $0.65-4.85$ & 0.28 \\
\hline PS at the beginning of second-line treatment & 6.98 & $1.80-35.9$ & $<0.01$ \\
\hline \multicolumn{4}{|l|}{ Best response at second-line treatment } \\
\hline non-PD/PD & 0.15 & $0.05-0.41$ & $<0.01$ \\
\hline Number of regimens employed after progression beyond first-line chemotherapy & 0.53 & $0.32-0.82$ & $<0.01$ \\
\hline
\end{tabular}

95\% CI, 95\% confidence interval; PD, progressive disease

associated with OS, whereas PFS and tumor shrinkage were moderately and weakly correlated with OS, respectively. In addition, $\mathrm{PS}$ at the beginning of second-line treatment, the best response to second-line treatment (non-PD vs. PD), and the number of regimens employed after progression following first-line chemotherapy, independently affected PPS.

The validity of surrogate endpoints has been previously determined through meta-analyses $[18,19]$. In recent years, biostatisticians have proposed a wide variety of measures for validating surrogate endpoints [20,21]. Although tumor response and PFS are potential surrogate endpoints for OS in extensive-stage small cell lung cancer [22], their validity is controversial in advanced NSCLC [23]. Broglio et al. recently focused on PPS, which they termed as survival post progression (defined as OS minus PFS), in a hypothetical clinical trial setting under the assumption that treatment affected PFS but not PPS [2]. Recently, PPS was found to be strongly associated with OS after first-line chemotherapy for advanced NSCLC in a clinical trial-level $[8,9]$.

Our results do not correspond with some previous results that have indicated that tumor response and PFS are surrogate endpoints for OS in advanced NSCLC $[24,25]$. We analyzed our results pertaining to first-line therapy, and they suggested that PFS and tumor response did not adequately reflect OS in such settings. We found that PFS was much shorter than PPS, and thus, PPS was closely related to OS-the relationship was linear (Figures 3A, 3B). The fact that PPS accounted for the most part of OS suggests that the chemotherapy used was too weak for PFS to prolong OS. Thus, in clinical trials with patients expected to have a short PFS after first-line chemotherapy such as patients without driver mutations, as was the case in our study, factors that affect PPS need to be controlled.

According to trial-level data for advanced NSCLC, long PPS was associated with a good PS and the use of first-line 


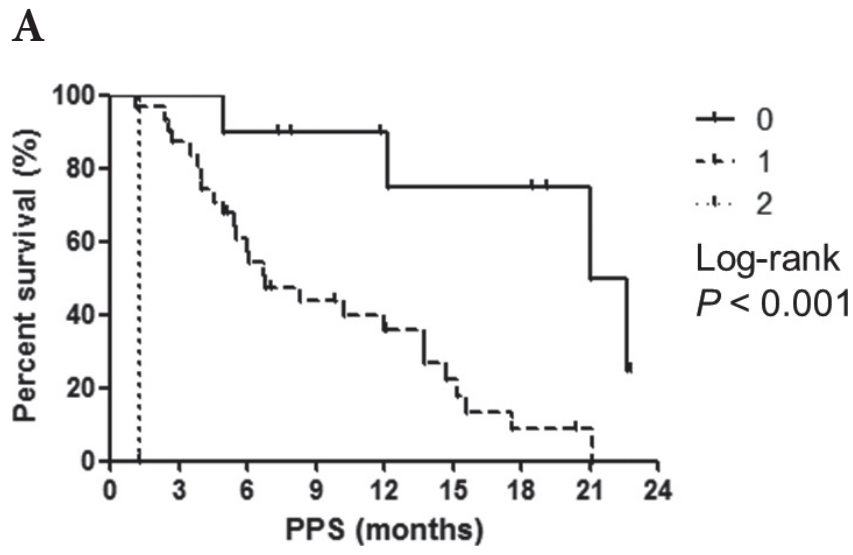

B
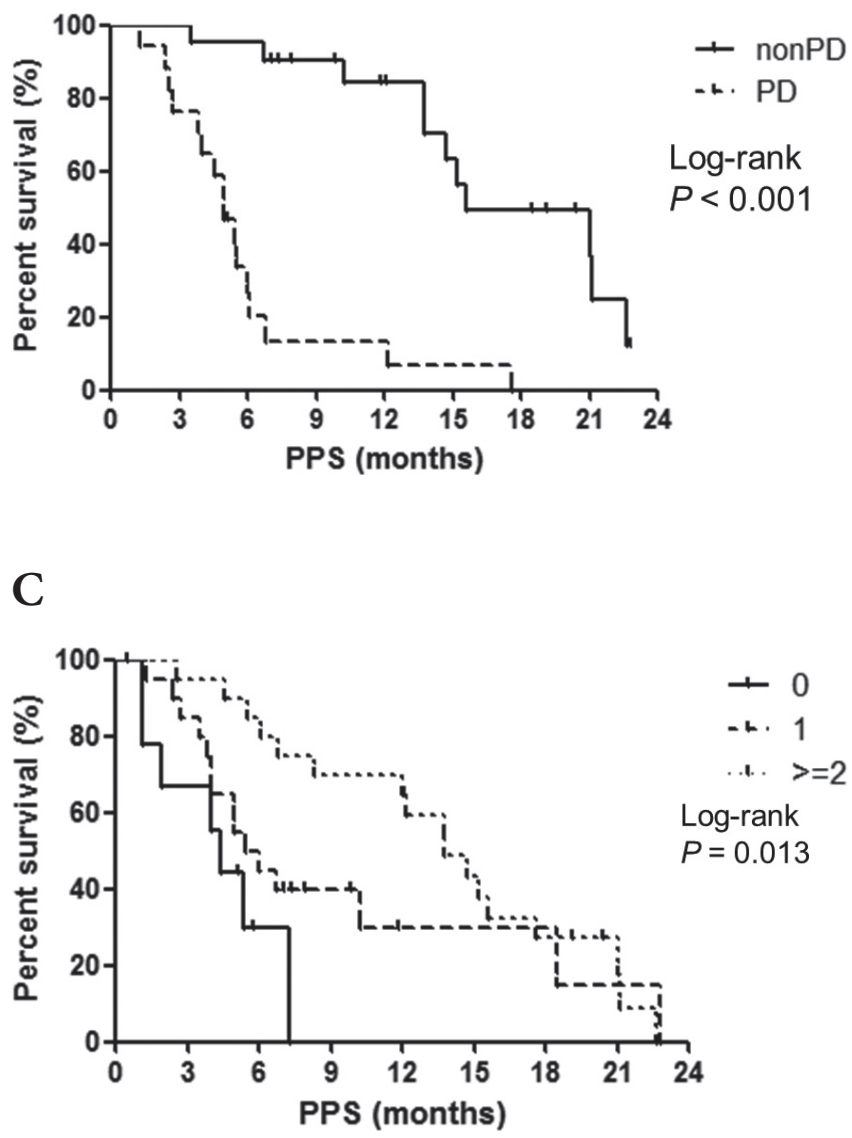

Figure 4. A. Kaplan-Meier plots showing post-progression survival according to performance status (PS) at the beginning of second-line treatment. PS 0, median $=21.8$ months; PS 1 , median $=6.7$ months; PS 2 , median $=1.3$ months. B. Kaplan-Meier plots showing post-progression survival, according to the best response following second-line treatment. non-progression disease, median $=15.6$ months; progression disease, median $=4.9$ months. C. Kaplan-Meier plots showing post-progression survival, according to the number of regimens after progression. none, median $=4.4$ months; 1 regimen, median $=5.7$ months; $\geqq 2$ regimens, median $=13.7$ months monotherapy and a molecular targeted agent [8]. However, to date, factors affecting PPS according to individual-level data of patients with advanced NSCLC are unclear. We attempted to explore the prognostic value of baseline factors for PPS. We found that the PS at the beginning of second-line treatment, the best response after second-line treatment, and the number of regimens employed after progression following first-line chemotherapy were strongly related to PPS. Moreover, we confirmed these relationships by log-rank tests. To our knowledge, this study is the first to report on individual-level factors affecting PPS in patients with advanced NSCLC. Our findings suggest that patients with good PS at the beginning of second-line treatment achieve disease stabilization after progression following first-line chemotherapy. These patients are also likely to be able to continue chemotherapy and achieve prolonged PPS, which is associated with OS prolongation. The number of treatment regimens used after progression following first-line chemotherapy is likely the result of the increasing number of active compounds, such as docetaxel, amrubicin, S1, and erlotinib, which are available for second- or third-line chemotherapy for advanced NSCLC. In fact, a number of different compounds were used to treat our patients, as shown in Table 2.

This study has several limitations. First, the sample size was small. However, because the number of advanced nonsquamous NSCLC patients treated with first-line cisplatin and pemetrexed, who do not have EGFR mutations or $A L K$ fusion genes are limited at a single institution, this limitation is difficult to overcome. This is especially true because the purpose of this study was to analyze patients with similar backgrounds. Second, we could not thoroughly evaluate treatments after progression following second-line chemotherapy. However, we consider the results of the present investigation worthwhile because there were few patients receiving thirdline or subsequent chemotherapy.

In conclusion, using individual-level data, PFS and tumor response appeared not to be ideal surrogates for OS in patients with advanced non-squamous NSCLC, without an oncogenic driver mutation and therefore limited options for subsequentline chemotherapy. In these patients, PPS was strongly associated with OS and a PFS advantage was not associated with an OS advantage because of the increasing influence of PPS on OS. In addition, the PS at the beginning of secondline treatment, the best response after second-line treatment (non-PD/PD), and the number of regimens employed after disease progression following first-line chemotherapy were prognostic factors for PPS. In other words, we suggest that the treatment course after progression following first-line chemotherapy greatly influences OS. We believe these results are worth validating with regard to their generalizability to other larger populations.

Acknowledgements: We wish to thank Ms. Mutsumi Yamazaki, Mr. Taiki Miyauchi, Drs. Kazushige Wakuda, Takuya Oyakawa, Madoka Kimura, Asuka Tsuya, Yukiko Nakamura, and Kyoichi Kaira for their assistance in preparing this manuscript. 


\section{References}

[1] SIEGEL R, DESANTIS C, VIRGO K, STEIN K, MARIOTTO A, et al. Cancer treatment and survivorship statistics, 2012. CA Cancer J Clin. 2012; 62: 220-241. http://dx.doi.org/10.3322/ $\underline{\text { caac. } 21149}$

[2] BROGLIO KR, BERRY DA. Detecting an overall survival benefit that is derived from progression-free survival. J Natl Cancer Inst. 2009; 101: 1642-1649. http://dx.doi.org/10.1093/ jnci/djp369

[3] SORIA JC, MASSARD C, LE CHEVALIER T. Should progression-free survival be the primary measure of efficacy for advanced nsclc therapy? Ann Oncol. 2010; 21: 2324-2332. http://dx.doi.org/10.1093/annonc/mdq204

[4] RECK M, VON PAWEL J, ZATLOUKAL P, RAMLAU R, GORBOUNOVA V, et al. Phase iii trial of cisplatin plus gemcitabine with either placebo or bevacizumab as first-line therapy for nonsquamous non-small-cell lung cancer: Avail. J Clin Oncol. 2009; 27: 1227-1234. http://dx.doi.org/10.1200/ JCO.2007.14.5466

[5] SAAD ED, KATZ A, BUYSE M. Overall survival and postprogression survival in advanced breast cancer: A review of recent randomized clinical trials. J Clin Oncol. 2010; 28: 1958-1962. http://dx.doi.org/10.1200/JCO.2009.25.5414

[6] SUNDAR S, WU J, HILLABY K, YAP J, LILFORD R. A systematic review evaluating the relationship between progression free survival and post progression survival in advanced ovarian cancer. Gynecol Oncol. 2012; 125: 493-499. http://dx.doi.org/10.1016/j.ygyno.2011.12.420

[7] PETRELLI F, BARNI S. Correlation of progression-free and post-progression survival with overall survival in advanced colorectal cancer. Ann Oncol. 2013; 24: 186-192. http://dx.doi. org/10.1093/annonc/mds289

[8] HOTTA K, KIURA K, FUJIWARA Y, TAKIGAWA N, HISAMOTO A, et al. Role of survival post-progression in phase iii trials of systemic chemotherapy in advanced nonsmall-cell lung cancer: A systematic review. PLoS One. 2011; 6: e26646. http://dx.doi.org/10.1371/journal.pone.0026646

[9] HAYASHI H, OKAMOTO I, MORITA S, TAGURI M, NAKAGAWA K. Postprogression survival for first-line chemotherapy of patients with advanced non-small-cell lung cancer. Ann Oncol. 2012; 23: 1537-1541. http://dx.doi. org/10.1093/annonc/mdr487

[10] SCHILLER JH, HARRINGTON D, BELANI CP, LANGER C, SANDLER A, et al. Comparison of four chemotherapy regimens for advanced non-small-cell lung cancer. N Engl J Med. 2002; 346: 92-98. http://dx.doi.org/10.1056/NEJMoa011954

[11] SCAGLIOTTI GV, DE MARINIS F, RINALDI M, CRINO L, GRIDELLI C, et al. Phase iii randomized trial comparing three platinum-based doublets in advanced non-small-cell lung cancer. J Clin Oncol. 2002; 20: 4285-4291. http://dx.doi. org/10.1200/JCO.2002.02.068

[12] KOSMIDIS P, MYLONAKIS N, NICOLAIDES C, KALOPHONOS C, SAMANTAS E, et al. Paclitaxel plus carboplatin versus gemcitabine plus paclitaxel in advanced non-small-cell lung cancer: A phase iii randomized trial. J Clin Oncol. 2002; 20: 3578-3585. http://dx.doi.org/10.1200/JCO.2002.12.112
[13] KORTSIK C, ALBRECHT P, ELMER A. Gemcitabine and carboplatin in patients with locally advanced or metastatic non-small cell lung cancer: A prospective phase ii study. Lung Cancer. 2003; 40: 85-90. http://dx.doi.org/10.1016/S01695002(02)00526-3

[14] HIRSCH FR, SPREAFICO A, NOVELLO S, WOOD MD, SIMMS L, et al. The prognostic and predictive role of histology in advanced non-small cell lung cancer: A literature review. J Thorac Oncol. 2008; 3: 1468-1481. http://dx.doi.org/10.1097/ ITO.0b013e318189f551

[15] SCAGLIOTTI GV, PARIKH P, VON PAWEL J, BIESMA B, VANSTEENKISTE J, et al. Phase iii study comparing cisplatin plus gemcitabine with cisplatin plus pemetrexed in chemotherapy-naive patients with advanced-stage non-small-cell lung cancer. J Clin Oncol. 2008; 26: 3543-3551. http://dx.doi. org/10.1200/JCO.2007.15.0375

[16] INOUE A, KOBAYASHI K, MAEMONDO M, SUGAWARA S, OIZUMI S, et al. Updated overall survival results from a randomized phase iii trial comparing gefitinib with carboplatin-paclitaxel for chemo-naive non-small cell lung cancer with sensitive egfr gene mutations (nej002). Ann Oncol. 2013; 24: 54-59. http://dx.doi.org/10.1093/annonc/ mds214

[17] EISENHAUER EA, THERASSE P, BOGAERTS J, SCHWARTZ LH, SARGENT D, et al. New response evaluation criteria in solid tumours: Revised recist guideline (version 1.1). Eur J Cancer. 2009; 45: 228-247. http://dx.doi.org/10.1016/ j.ejca.2008.10.026

[18] JOHNSON KR, RINGLAND C, STOKES BJ, ANTHONY DM, FREEMANTLE N, et al. Response rate or time to progression as predictors of survival in trials of metastatic colorectal cancer or non-small-cell lung cancer: A meta-analysis. Lancet Oncol. 2006; 7: 741-746. http://dx.doi.org/10.1016/S14702045(06)70800-2

[19] HOTTA K, FUJIWARA Y, MATSUO K, KIURA K, TAKIGAWA N, et al. Time to progression as a surrogate marker for overall survival in patients with advanced non-small cell lung cancer. J Thorac Oncol. 2009; 4: 311-317. http://dx.doi. org/10.1097/JTO.0b013e3181989bd2

[20] WEIR CJ, WALLEY RJ. Statistical evaluation of biomarkers as surrogate endpoints: A literature review. Stat Med. 2006; 25: 183-203. http://dx.doi.org/10.1002/sim.2319

[21] FLEISCHER F, GASCHLER-MARKEFSKI B, BLUHMKI E. A statistical model for the dependence between progression-free survival and overall survival. Stat Med. 2009; 28: 2669-2686. http://dx.doi.org/10.1002/sim.3637

[22] FOSTER NR, QI Y, SHI Q, KROOK JE, KUGLER JW, et al. Tumor response and progression-free survival as potential surrogate endpoints for overall survival in extensive stage small-cell lung cancer: Findings on the basis of north central cancer treatment group trials. Cancer. 2011; 117: 1262-1271. http://dx.doi.org/10.1002/cncr.25526

[23] BERGHMANS T, PASLEAU F, PAESMANS M, BONDUELLE Y, CADRANEL J, et al. Surrogate markers predicting overall survival for lung cancer: Elcwp recommendations. Eur Respir J. 2012; 39: 9-28. http://dx.doi.org/10.1183/ $\underline{09031936.00190310}$ 
[24] TSUJINO K, KAWAGUCHI T, KUBO A, AONO N, NAKAO $\mathrm{K}$, et al. Response rate is associated with prolonged survival in patients with advanced non-small cell lung cancer treated with gefitinib or erlotinib. J Thorac Oncol. 2009; 4: 994-1001. http://dx.doi.org/10.1097/JTO.0b013e3181a94a2f
[25] LI X, LIU S, GU H, WANG D. Surrogate end points for survival in the target treatment of advanced non-small-cell lung cancer with gefitinib or erlotinib. J Cancer Res Clin Oncol. 2012; 138: 1963-1969. http://dx.doi.org/10.1007/s00432$\underline{012-1278-\mathrm{Z}}$ 